\title{
Assessment of glued timber integrity by limited-angle microfocus X-ray computed tomography
}

\author{
Journal Article \\ Author(s): \\ Sanabria, Sergio J.; Wyss, Peter; Neuenschwander, Jürg; Niemz, Peter; Sennhauser, Urs \\ Publication date: \\ 2011-11 \\ Permanent link: \\ https://doi.org/10.3929/ethz-b-000027578
}

Rights / license:

In Copyright - Non-Commercial Use Permitted

Originally published in:

European Journal of Wood and Wood Products 69(4), https://doi.org/10.1007/s00107-010-0509-8 


\title{
Assessment of glued timber integrity by limited-angle microfocus $\mathrm{X}$-ray computed tomography
}

\author{
Sergio J. Sanabria $\cdot$ Peter Wyss · \\ Juerg Neuenschwander • Peter Niemz • Urs Sennhauser
}

Received: 9 April 2010 / Published online: 2 December 2010

C) Springer-Verlag 2010

\begin{abstract}
Glued timber products have an extensive range of applications in construction. In this work a Microfocus $\mathrm{X}$-ray Computed Tomography method was developed to inspect gluing defects in timber samples and was applied successfully on experimental data. The bonding plane was segmented into glued and non-glued regions and imaged with $5 \mathrm{~mm}$ resolution. Moreover, the gap topology between timber lamellas was precisely characterised. A limited-angle reconstruction with anisotropic frame binning together with a specific glue line readout method efficiently filters out undesired wood structure highlighting the information of the adhesive joint. This method imposes limitations on the size of the specimen in only one dimension. The presence and absence of glue could be detected for glue line thicknesses over $50 \mu \mathrm{m}$ and air gaps larger than $150 \mu \mathrm{m}$ could be characterised. Several information reduction approaches were combined in the reconstruction process to implement the assessment of a $100 \times 100 \mathrm{~mm}^{2}$ bonding plane in less than $40 \mathrm{~s}$.
\end{abstract}

\section{Detektion von Fehlverklebungen in Holzbauteilen mittels Mikrofokus Röntgen-Computertomographie}

Zusammenfassung Holzverklebungen gewinnen zunehmend an Bedeutung. Im Rahmen dieser Arbeit wurde ein Mikrofokus Röntgen-Computertomographie Messverfahren

S.J. Sanabria $(\bowtie) \cdot$ P. Wyss · J. Neuenschwander · U. Sennhauser Electronics/Metrology/Reliability Laboratory, Empa, Swiss Federal Laboratories for Materials Science and Technology, Ueberlandstrasse 129, 8600 Duebendorf, Switzerland e-mail: sergio.sanabria@empa.ch

P. Niemz

Institute for Building Materials, Wood Physics, ETH Zurich,

Zurich, Switzerland zur Beurteilung von Fehlverklebungen in Holzbauteilen entwickelt und in experimentellen Versuchen erfolgreich überprüft. Fehlverklebungen und die Topologie der Klebfugen wurden mit einer räumlichen Auflösung von $5 \mathrm{~mm}$ abgebildet. Verfahrensspezifische Bildrekonstruktions- und Klebfugen-Auslesealgorithmen mit eingeschränktem Aufnahmewinkelbereich filtern unerwünschte Holzstrukturen heraus und heben die Leimschicht hervor. Die Größe der Holzbauteile ist bei diesem Messverfahren nur in einer Dimension beschränkt. Die An- und Abwesenheit von Klebstoff lässt sich für Leimfugen dicker als $50 \mu \mathrm{m}$ nachweisen; Luftspalten größer als $150 \mu \mathrm{m}$ sind feststellbar. Die Informations-Reduktionsverfahren ermöglichten die Beurteilung von $100 \times 100 \mathrm{~mm}^{2}$ verleimten Holzoberflächen in einer Messzeit von weniger als $40 \mathrm{~s}$.

\section{Introduction}

The conventional forms of sawn wood in construction have been replaced during recent years in favour of highly engineered glued timber products. The bonding quality needs to be assessed in order to maximise the life cycle of the constructions. Current European standardised methods rely on visual inspection or mechanical tests on selected specimens (EN 391:2001; EN 14080:2005). The development of a non-destructive glue line assessment procedure is an open research question. Infrared thermography detects changes in thermal conductivity or thermo-mechanics in delaminated wood veneer of a few millimetres thickness (Berglind and Dillenz 2003; Choi et al. 2008). Ultrasonics is an irreplaceable tool for adhesion testing due to its high sensitivity to delaminated interfaces and relatively low cost (Kabir et al. 2002; Maeva et al. 2004; Solodov et al. 2004; Dill-Langer et al. 2005; Hasenstab 2006). The main drawbacks are poor, coupling pressure dependent reproducibility and the difficulties of performing imaging with sufficient 
spatial resolution. Recently an air-coupled ultrasound system has been developed that is not limited by these shortcomings (Sanabria et al. 2010a).

Computed tomography (CT) allows for a full 3D reconstruction of the interior of a sample regardless of its exterior geometry. In the field of wood science there exist, amongst others, applications for imaging, segmentation and quantification of bark, knots, heartwood/sapwood boundary, spiral grain, moisture transport, decay, cracks, voids and year ring structure (Niemz et al. 1997; Schmoldt et al. 2000; Oja 2000; Sepulveda et al. 2002; Bucur 2003; Rinnhofer et al. 2003; Espinoza et al. 2005; Bhandarkar et al. 2006; Longuetaud et al. 2007; Scheepers et al. 2007; Entacher et al. 2007; Mannes et al. 2009a). However, few works on CT glue line assessment in timber components are available. Commercial $\mathrm{X}$-ray density profiler systems perform a global assessment of the glue line on small specimens $\left(50 \times 50 \mathrm{~mm}^{2}\right)$ with a resolution down to $10 \mu \mathrm{m}$ (QDP-01X, Quintek Measurement Systems, Knoxville, TN, USA; Dense-Lab X, Electronic Wood Systems Int., Beaverton, OR, USA; DAX 5000, Fagus-GreCon Greten GmbH \& Co. KG, Alfeld, Germany). Sirr and Waddle (1999) performed X-ray CT imaging of animal glue repair in Stradivarius violins; Morigi et al. (2007) visualised stucco fillings in paintings on wood; tomoslices showing the presence of glue in finger joints have been obtained using X-rays (Niemz et al. 1999; $\mathrm{Hu}$ and Gagnon 2007) and fast neutron CT (Mannes et al. 2009b; Osterloh et al. 2008).

In this work the application of Microfocus Computed Tomography $(\mu \mathrm{CT})$ to glue line inspection of timber laminates is shown. A limited-angle inspection procedure is used which greatly reduces data acquisition and reconstruction times, imposes limitations to only one of the dimensions of the specimen and eliminates undesired wood structure from the tomoslices. Next, specific glue line readout and segmentation algorithms are presented, which retrieve a spatial map of the areas with and without adhesive within the bonding plane, providing also information on the topology of the gap between timber lamellas. Finally, the method is optimised by minimising the amount of input data required to perform a satisfactory glue line assessment.

\section{Materials and methods}

\subsection{Sample preparation and optic measurements}

A total of six glued timber samples were taken from the available pallet used in the air-coupled ultrasound investigations (Sanabria et al. 2010a). They each consisted of two common spruce (Picea abies Karst.) lamellas of dimensions $500 \times 100 \times 5 \mathrm{~mm}^{3}$ glued together to form a glued timber object of $500 \times 100 \times 10 \mathrm{~mm}^{3}$. The adhesive, a onecomponent moisture-curing polyurethane resin (HB 110,
Purbond AG, Sempach Station, Switzerland), was applied to one side of the lamellas with an amount of $200 \mathrm{~g} \mathrm{~m}^{-2}$. Only two areas of about $100 \times 30 \mathrm{~mm}^{2}$ on both left and right edges of the sample were glued. The lamellas were pressed together in a hydraulic press for 3 hours at a pressure of $0.8 \mathrm{~N} \mathrm{~mm}^{-2}$. Normalised climatic conditions $\left(T=20^{\circ} \mathrm{C}\right.$ and $\mathrm{RH}=65 \%$ ) were used for storage.

The cross-section of the samples is approximately perpendicular to the growth direction of the stem (R-T plane), the ring angle varying between $90^{\circ}$ (year rings perpendicular to the glue joint) and $45^{\circ}$. Aluminium sheets of 500 and $1000 \mu \mathrm{m}$ thickness were introduced in the central position of the specimens ( $250 \mathrm{~mm}$ from the edges) in order to achieve a defined air gap thickness distribution between nonglued wood lamellas (Fig. 1). The gap was measured from the external surfaces of the sample using an optical scanner with 600 dpi digital resolution. The thickness of the glue line and the air gap in the vicinity of the transition between glued and non-glued areas was characterised with a high resolution stereomicroscope with a zoom range of $7.8 \times-160 \times$ (M205C, Leica Microsystems GmbH, Wetzlar, Germany). After the investigations, the samples were broken up and the profile of the transition between glued and non-glued areas was highlighted with a pencil and recorded with the optical scanner.

\section{$2.2 \mathrm{X}$-ray data acquisition}

$\mathrm{X}$-ray measurements were performed with a laboratory cone beam $\mu \mathrm{CT}$ system optimised for non-destructive testing (Fig. 1). The source is a $160 \mathrm{kV}$ microfocus X-ray tube (TXD9160, Viscom AG, Hannover, Germany) with a transmission target consisting of diamond that was coated with a $3 \mu \mathrm{m}$ tungsten layer. The tube was operated at an acceleration voltage of $40 \mathrm{kV}$ and a nominal power of $30 \mathrm{~W}$ to obtain a focal spot size of approximately $50 \mu \mathrm{m}$ with sufficient signal-to-noise ratio. The detector is an X-ray flat panel sensor (7942CA-02, Hamamatsu Photonics K. K, Hamamatsu City, Japan) with a sensitive area of $120 \times 120 \mathrm{~mm}^{2}$ and a pixel size of $50 \mu \mathrm{m}$, consisting of a CsI:Tl scintillator plate with needle structure. An exposure time of $1 \mathrm{~s}$ was used and the aluminium front-face of the detector was replaced with black paper so as to increase the efficiency for the main part of the tube spectrum (around $25 \mathrm{keV}$ ).

The glued timber samples were placed on a motorised low runout rotary stage located between the X-ray tube and the detector and rotated with specific angular steps of $0.15^{\circ}$ or $0.2^{\circ}$. For each angle $\Phi_{k}$ the logarithmic X-ray attenuation between the source and the pixels of the detector $\left(u_{i}, v_{j}\right)$ was recorded as a projection or frame $P_{\Phi_{k}}\left(u_{i}, v_{j}\right)$ of 12 bits grey values; light grey corresponds to high attenuation. At $\Phi_{k}=0^{\circ}$, the glue line plane is perpendicular to the detector and aligned with the main axis of the cone beam. Limited 
Fig. $1 \mu \mathrm{CT}$ measurement setup and definition of sample and $\mathrm{X}$-ray detector coordinate systems

Abb. $1 \mu$ CT Messaufbau und Koordinatensysteme für Holzproben und Röntgendetektor
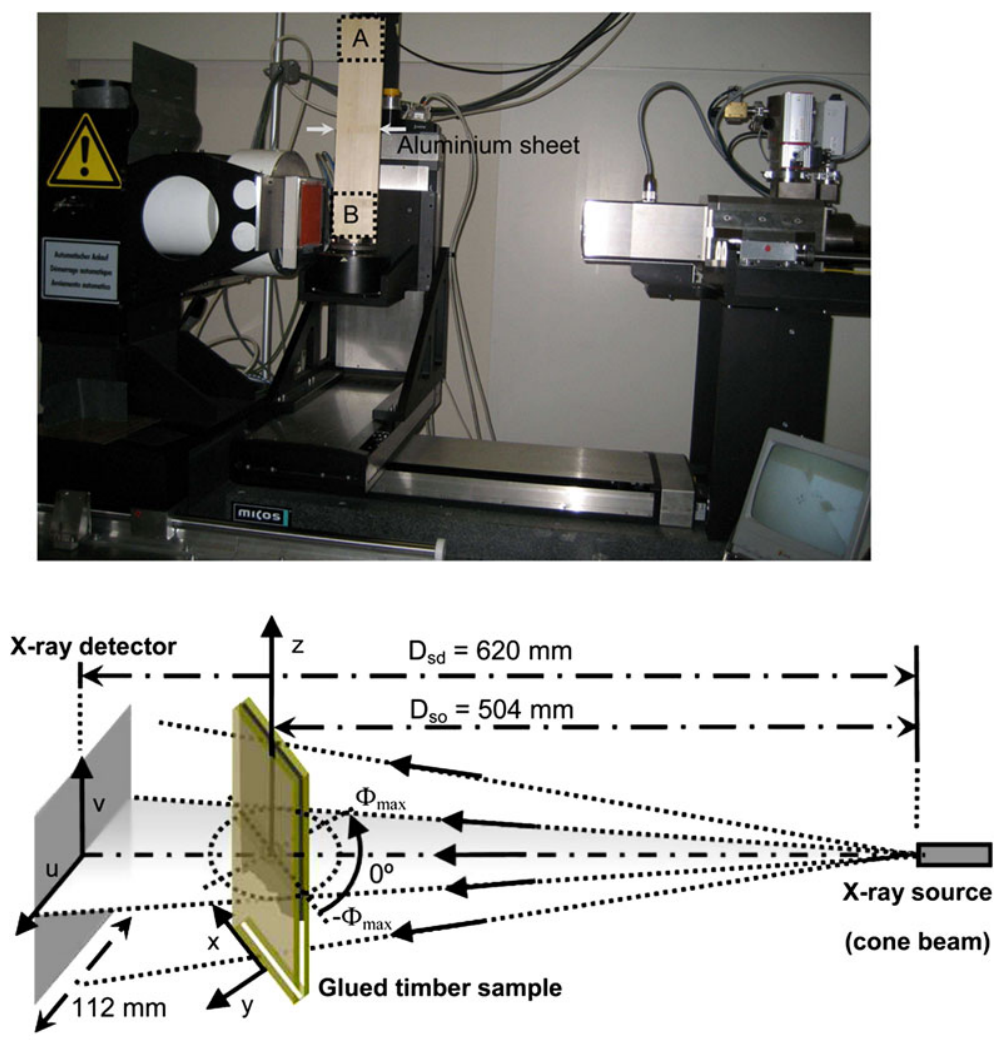

angular ranges $\left[-\Phi_{\max }, \Phi_{\max }\right]$ were obtained by considering only a limited number of equispaced projections in the reconstruction algorithm. The distances between source and detector $\left(D_{s d}=620 \mathrm{~mm}\right)$ and between source and sample rotation axis $\left(D_{s o}=504 \mathrm{~mm}\right)$ were chosen to achieve the largest possible field of view in the detector $(112 \mathrm{~mm})$ with a sample-related pixel size of $41 \mu \mathrm{m}$. Two $\mu \mathrm{CT}$ measurements A and B per sample were performed, for each of them a volume of $100 \times 100 \times 10 \mathrm{~mm}^{3}$ containing glued and nonglued timber was reconstructed.

\subsection{Limited-angle reconstruction}

Figure 2 summarises the main signal processing steps applied to the measured $\mu \mathrm{CT}$ data. The theoretical interpretation of the limited-angle method is based on the Fourier Slice Theorem (Kak and Slaney 1988). For an inspection limited to the angular interval $\left[-\Phi_{\max }, \Phi_{\max }\right]$ the $2 \mathrm{D}$ Fourier transform of the CT tomoslices is only defined for $\left[\pi / 2-\Phi_{\max }, \pi / 2+\Phi_{\max }\right]$; therefore, image features with angles outside $\left[-\Phi_{\max }, \Phi_{\max }\right]$ are filtered out. The glue line information is restricted to a quasi-horizontal angular range (Fig. 3). Anatomical wood features such as the year ring structure are distributed over the full angular range and are eliminated in the reconstruction process. A modification of the FDK cone beam filtered backprojection reconstruction algorithm (Feldkamp et al. 1984; Kak and Slaney 1988) was implemented with single-threaded Matlab ${ }^{\circledR}$ software in a computer with a $2.83 \mathrm{GHz}$ Intel ${ }^{\circledR}$ Xeon ${ }^{\circledR}$ E5440 processor and 32.0 GB of RAM memory. A Shepp-Logan filter was applied to $P_{\Phi_{k}}\left(u_{i}, v_{j}\right)$ for grey level contrast optimisation. The limited-angle backprojection was implemented by summing $N_{\Phi}$ scaled and filtered frames $\tilde{P}_{\Phi_{k}}(\tilde{u}, \tilde{v})$ using a bilinear interpolation procedure:

$$
\begin{aligned}
& \mu\left(x_{l}, y_{m}, z_{n}\right) \propto \sum_{k=1}^{N_{\Phi}} \frac{1}{U^{2}} \tilde{P}_{\Phi_{k}}(\tilde{u}, \tilde{v}) \\
& \tilde{u}\left(x_{l}, y_{m}, \Phi_{k}\right)=\frac{D_{s d}}{D_{s o}} \frac{x_{l} \sin \Phi_{k}+y_{m} \cos \Phi_{k}}{U} \\
& \tilde{v}\left(x_{l}, y_{m}, z_{n}, \Phi_{k}\right)=\frac{D_{s d}}{D_{s o}} \frac{z_{n}}{U} \\
& U\left(x_{l}, y_{m}, \Phi_{k}\right)=1+\frac{1}{D_{s o}} x_{l} \cos \Phi_{k}-\frac{1}{D_{s o}} y_{m} \sin \Phi_{k}
\end{aligned}
$$

where $\mu\left(x_{l}, y_{m}, z_{n}\right)$ is the reconstructed attenuation coefficient. Hereafter, the discretization subscripts $i, j, k, l, m$ and $n$ are dropped in order to simplify notation. The amount of reconstruction data was minimised with a qualitative analysis of the glue line segmentation results. Larger detector pixel sizes were implemented with overlapped averaging of $P_{\Phi}(u, v)$ followed by anisotropic binning; the reconstruction step in $y$ equals the binned pixel size in $u$, the steps in $x$ and $z$ correspond to the one in $v$. Local tomography allowed for further data reduction by cropping $P_{\Phi}(u, v)$ in $u$ to the effective field of view $F O V^{e}$ necessary to reconstruct 


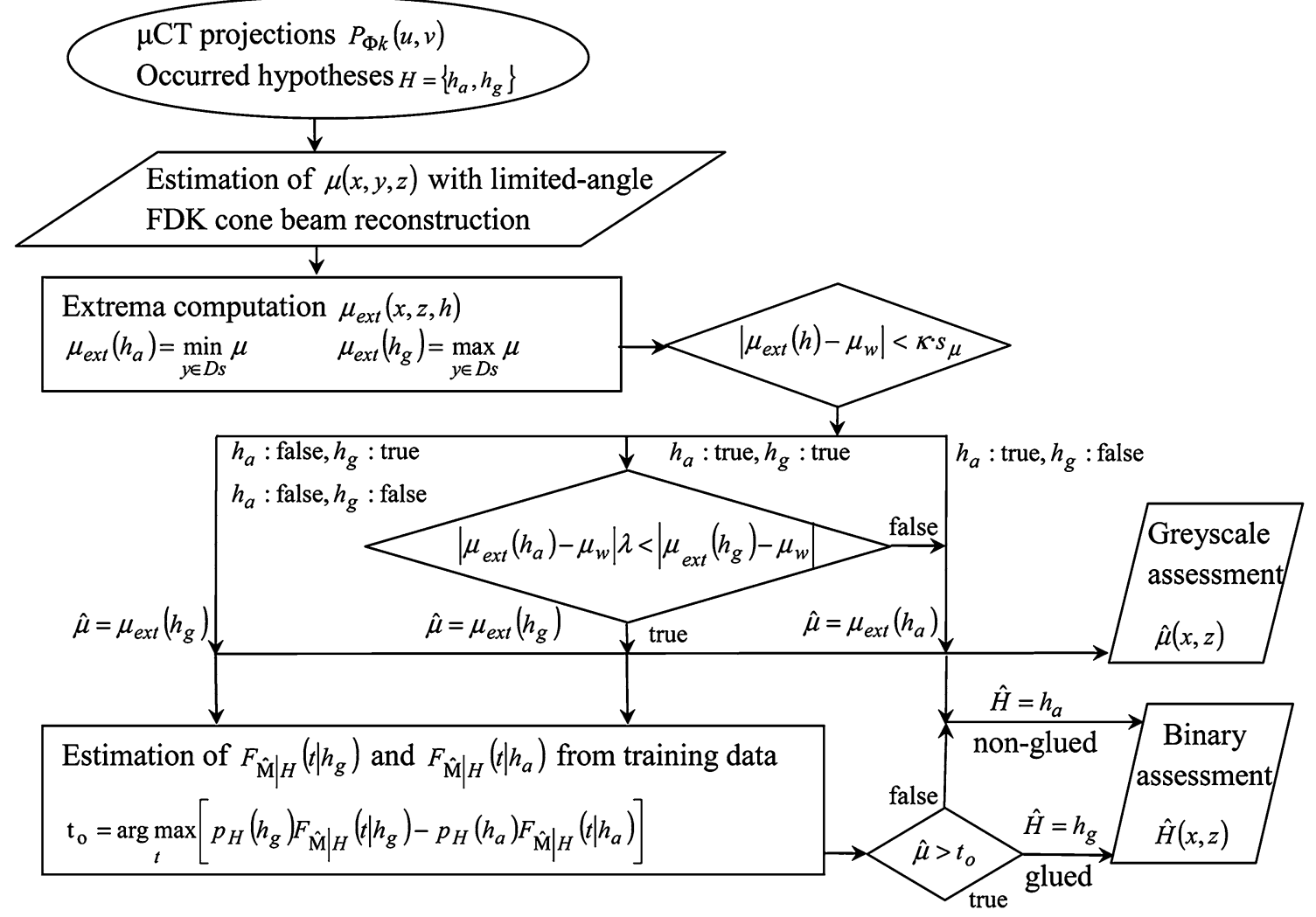

Fig. 2 Flow diagram of glue line assessment algorithm

Abb. 2 Flussdiagramm des Klebfugen-Auslesealgorithmus

a volume containing the glue line plane. $F O V^{e}$ was calculated with taking only into account ray trajectories between source and detector that go through the volume:

$$
\begin{gathered}
F O V^{e}=\frac{2 D_{s d} \sin \left(\Phi_{\max }+\beta\right)}{D_{s o} / r-\cos \left(\Phi_{\max }+\beta\right)} \\
\beta=\arctan \frac{\xi}{w}, r=\frac{1}{2} \sqrt{\xi^{2}+w^{2}}
\end{gathered}
$$

where $w$ is the width of the sample in direction $x$ at $\Phi=0^{\circ}$ and $\xi$ is the thickness reconstructed across the glue line. For the setup with $w=100 \mathrm{~mm}$ and $\xi=10 \mathrm{~mm}$ the glue line assessment algorithms performed well.

\subsection{Glue line readout algorithm and modified MAP segmentation}

The segmentation of glued and non-glued areas was addressed as a binary hypothesis test, with $h_{g}$ the hypothesis of presence of glue and $h_{a}$ the hypothesis of occurrence of an air gap between timber lamellas. First a specific glue line readout applied to the tomoslices (Fig. 2) reduced the 3D tomogram $\mu(x, y, z)$ to a summarised $2 \mathrm{D}$ greyscale image of the bonding plane $\hat{\mu}(x, z)$. The algorithm assumes that the X-ray attenuation coefficient of glue is higher than the mean wood attenuation coefficient. This is typically the case for wood species and adhesives used in construction (Dunky and Niemz 2002). In the case of non-glued material, an air gap with a reduced attenuation coefficient is expected. Grey level profiles were drawn across the glue line for each bonding plane position (Fig. 3). The absolute extrema of each profile $\mu_{\text {ext }}(x, z, h)$ were calculated; for $h_{g}$ and $h_{a}$ absolute minima and maxima were searched, respectively:

$\mu_{\text {ext }}\left(x, z, h_{a}\right)=\min _{y \in D_{s}} \mu(x, y, z)$
$\mu_{\text {ext }}\left(x, z, h_{g}\right)=\max _{y \in D_{s}} \mu(x, y, z)$

where $D_{s}$ is an interval where the glue line is certain to be found, typically $\left|D_{s}\right|=\xi$. The mean $\mu_{w}$ and standard deviation $s_{\mu}$ of the grey level in the wood pixels around the glue line were also computed for each profile. A preliminary decision was taken on $h_{a}$ or $h_{g}$ by locally testing the following inequalities:

$$
\begin{aligned}
& \left|\mu_{\text {ext }}(h)-\mu_{w}\right|<\kappa \cdot s_{\mu} \\
& \left|\mu_{\text {ext }}\left(h_{a}\right)-\mu_{w}\right| \lambda<\left|\mu_{\text {ext }}\left(h_{g}\right)-\mu_{w}\right|
\end{aligned}
$$

where $\kappa$ and $\lambda$ are two empirical constants. The first inequality checks the contrast of the extrema with respect to background noise caused by wood heterogeneity (typically $\kappa=2$ is sufficient). The second one determines which hypothesis 
Fig. $3 \mu \mathrm{CT}$ tomoslices. a Non-glued material, full-angle tomography. b Non-glued, limited-angle. c Glued, full-angle. d Glued, limited-angle

Abb. $3 \mu$ CT Schnittbilder. a Nicht verklebtes Holz, Vollwinkel Tomographie.

b Nicht verklebt, eingeschränkter Winkelbereich. c Verklebt, Vollwinkel. d Verklebt, eingeschränkter Winkelbereich
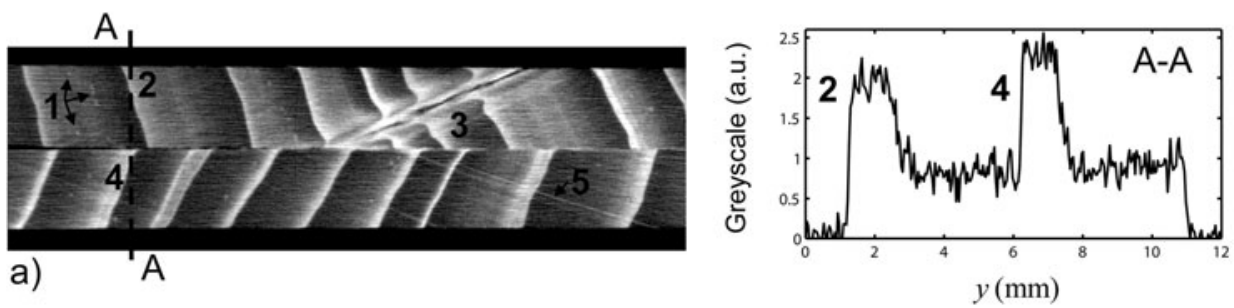

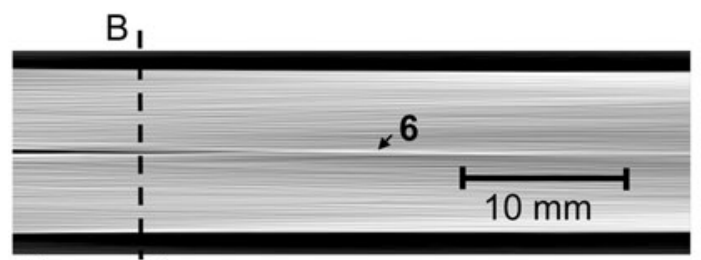

b)
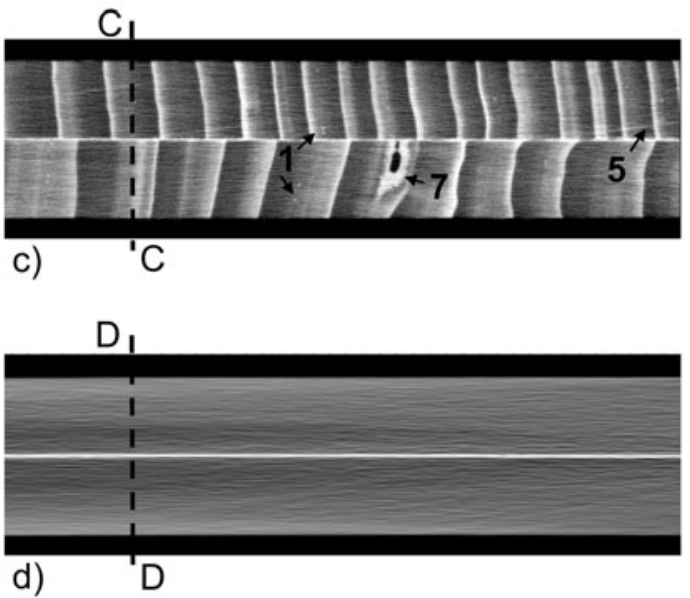
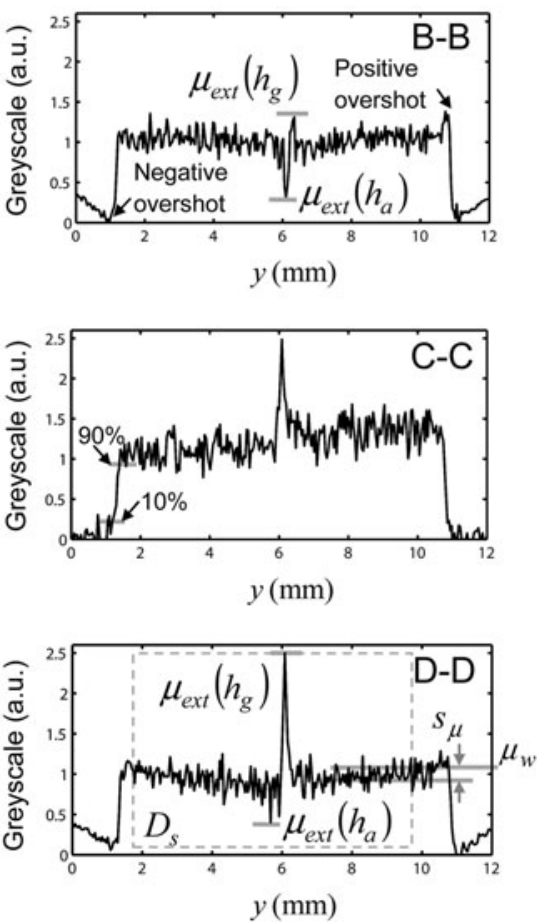

has highest effective contrast. An optimum performance was achieved for $\lambda=2$ by substituting $\left|\mu_{a}-\mu_{w}\right| \lambda=\left|\mu_{g}-\mu_{w}\right|$, with $\mu_{g}$ and $\mu_{a}$ the mean X-ray attenuation coefficients observed for adhesive and air, respectively. An absolute minimum, with sufficient contrast with respect to $s_{\mu}$ and higher than the absolute maximum computed for the same position, was identified directly as an air gap $h_{a}$, with $\hat{\mu}=\mu_{\text {ext }}\left(h_{a}\right)$. Other possible outcomes of Eq. 4 correspond to either glued material or non-glued material with an air gap of thickness below the resolution of the measurement; in these cases $\hat{\mu}=\mu_{\text {ext }}\left(h_{g}\right)$ was preliminarily stored.

The final segmentation step transformed the greyscale image $\hat{\mu}(x, z)$ into a binary image $\hat{H}(x, z)$ with possible outcomes $h_{a}$ and $h_{g}$. For pixels $\hat{\mu}=\mu_{\text {ext }}\left(h_{a}\right)$ directly $\hat{H}=h_{a}$. For pixels $\hat{\mu}=\mu_{\text {ext }}\left(h_{g}\right)$, a decision on either glued or non-glued timber was established using an optimum probabilistic grey level threshold $t_{o}$; values of $\hat{\mu}$ over $t_{o}$ were assigned to $\hat{H}=h_{g}$ and the rest were considered $\hat{H}=h_{a}$.

A single-threshold maximum a posteriori algorithm (STMAP) was designed to find $t_{o}$ based on training information acquired from the samples. This algorithm is a modification of the classical Bayesian hypothesis test (Van Trees 2001). The resulting optimum threshold is well defined and unique against incomplete estimates of the grey level probability density functions for glued and non-glued timber. The 3D joint probability density function of the measured X-ray attenuation coefficient $\hat{M}$ occurred hypothesis $H=\left\{h_{a}, h_{g}\right\}$ and estimated hypothesis $\hat{H}=\left\{h_{a}, h_{g}\right\}$ as a function of the threshold $t$ follows the following expression:

$$
\begin{aligned}
& f_{\hat{H}, H, \hat{M}}(\hat{h}, h, \hat{\mu}) \\
& \quad= \begin{cases}p_{H}(h) f_{\hat{M} \mid H}(\hat{\mu} \mid h) U(\hat{\mu}-t) & \hat{H}=h_{g} \\
p_{H}(h) f_{\hat{M} \mid H}(\hat{\mu} \mid h) U(t-\hat{\mu}) & \hat{H}=h_{a}\end{cases}
\end{aligned}
$$

The upper case letters $H, \hat{H}$ and $\hat{M}$ denote random variables and the lower case letters $h, \hat{\mu}$ and $\hat{\mu}$ realisations; $f_{\hat{M} \mid H}$ is the probability density function of the X-ray attenuation coefficient conditioned on the occurred hypothesis, $p_{H}(h)$ are hypotheses probabilities and $U(x)$ is the unitstep Heaviside function. The goodness of decision $D$ is a binary random variable with outcome "ok" if the estimated hypothesis equals the occurred hypothesis and "false" otherwise. Operating Eq. 5, the probability of a correct decision conditioned on the measured X-ray attenuation coefficient $p_{D \mid \hat{M}}$ ("ok"l $\left.\hat{\mu}\right)$ is calculated as 


$$
\begin{aligned}
& p_{D \mid \hat{M}}(\text { “"ok”| } \mid \hat{\mu}) \\
& =\frac{f_{\hat{H}, H, \hat{M}}\left(\hat{h}_{a}, h_{a}, \hat{\mu}\right) p_{H}\left(h_{a}\right)+f_{\hat{H}, H, \hat{M}}\left(\hat{h}_{g}, h_{g}, \hat{\mu}\right) p_{H}\left(h_{g}\right)}{f(\hat{\mu})} \\
& =\frac{p_{H}\left(h_{g}\right) f_{\hat{M} \mid H}\left(\hat{\mu} \mid h_{g}\right) U(\hat{\mu}-t)+p_{H}\left(h_{a}\right) f_{\hat{M} \mid H}\left(\hat{\mu} \mid h_{a}\right) U(t-\hat{\mu})}{p_{H}\left(h_{a}\right) f_{\hat{M} \mid H}\left(\hat{\mu} \mid h_{a}\right)+p_{H}\left(h_{g}\right) f_{\hat{M} \mid H}\left(\hat{\mu} \mid h_{g}\right)}
\end{aligned}
$$

The optimum threshold $t_{o}$ that maximises the probability of correct decision is

$$
\begin{gathered}
\left.t_{o}=\arg \max _{t} p_{D} \text { (“ok") }=\arg \max _{t} \int_{-\infty}^{\infty} p_{D \mid \hat{M}} \text { (“ok”l } \hat{\mu}\right) \mathrm{d} \hat{\mu} \\
=\arg \max _{t}\left[p_{H}\left(h_{g}\right) F_{\hat{M} \mid H}\left(t \mid h_{g}\right)\right. \\
\left.\quad-p_{H}\left(h_{a}\right) F_{\hat{M} \mid H}\left(t \mid h_{a}\right)\right]
\end{gathered}
$$

$F_{\hat{M} \mid H}(t \mid h)=\int_{-\infty}^{t} f_{\hat{M} \mid H}(\hat{\mu} \mid h) \mathrm{d} \hat{\mu}$

where $F_{\hat{M} \mid H}\left(\hat{\mu} \mid h_{g}\right)$ and $F_{\hat{M} \mid H}\left(\hat{\mu} \mid h_{a}\right)$ are cumulative probability distributions of the X-ray attenuation coefficient conditioned on the occurred hypotheses. $F_{\hat{M} \mid H}\left(\hat{\mu} \mid h_{g}\right)$ and $F_{\hat{M} \mid H}\left(\hat{\mu} \mid h_{a}\right)$ are estimated by integrating a histogram of training pixels for glued and non-glued regions, respectively. The main advantage of this procedure is that even if scarce or no histogram data is available for certain grey level values $\hat{\mu}$, the cumulative distributions $F_{\hat{M} \mid H}(\hat{\mu} \mid h)$ are well defined monotonically increasing functions. Moreover, once $t_{o}$ is available, the implementation of the segmentation process is portable to very simple hardware architectures.

\section{Results and discussion}

Figure 3 shows typical tomoslices for well-glued and nonglued timber, reconstructed with full-angle (1800 projections with $0.2^{\circ}$ steps) and limited-angle (19 projections, angular range of $\left.\pm 1.8^{\circ}\right) \mu \mathrm{CT}$. The full-angle results clearly reveal the year ring structure with significantly stronger X-ray attenuation in the high density latewood (LW) zone (2) than in the lower density earlywood (EW) regions. Several anatomical features such as axial resin ducts (1), knots (3), wood rays (5), and resin pockets (7) can be observed. The density was computed from a linear calibration with the grey level values $\mu$, using the nominal densities of air $\left(1.2 \mathrm{~kg} \mathrm{~m}^{-3}\right)$ and polyurethane adhesive $\left(1100 \mathrm{~kg} \mathrm{~m}^{-3}\right)$ as reference values. The resulting wood density values are 260-340 $\mathrm{kg} \mathrm{m}^{-3}$ for EW and $800-1100 \mathrm{~kg} \mathrm{~m}^{-3}$ for LW. In LW areas, $\mu$ values of the same magnitude order as the ones for adhesive can be observed (2). This can lead to failure in the glue line segmentation when the year ring structure intersects the glue line (4). Due to the limited spatial resolution of the tomograms, the LW information is smeared into the glue joint. This effect can be clearly seen in the A-A profile, where the EW/LW transition (4) hides the air gap information, leading to the false interpretation that there is glue between timber lamellas $h_{g}$. In the case of Fig. $3 \mathrm{c}$ the profile $\mathrm{C}-\mathrm{C}$ has been drawn across $\mathrm{EW}$; a maximum here indicates the presence of adhesive in the glue line.

The limited-angle reconstruction effectively filters out the year ring structure and other anatomical wood features from the tomograms, resulting in a homogeneous grey level in the wood regions (Figs. $3 \mathrm{~b}$ and d). Comparing A-A with its limited-angle version B-B, one observes that LW features (2) and (4) are not present in the latter; however, the information of the glue line is preserved. A clear grey level minimum in B-B is now correctly interpreted as nonglued wood $h_{a}$. In the case of profile C-C, the improvement achieved in D-D is not so evident. From several similar observations it can be concluded that with limited-angle reconstruction, the grey level contrast between adhesive and wood and the grey level variability for wood are of the same order of magnitude as the values measured in EW regions with full-angle reconstruction. The grey level variations in the limited-angle case follow a Gaussian distribution.

Figure $3 \mathrm{~b}$ shows that false maxima are still possible in the limited-angle reconstruction for very thin air gaps between timber lamellas (6). This effect justifies the necessity for the last segmentation step of the algorithm to differentiate between glued regions and thin air gaps. A possible explanation is linked to an edge distortion effect; for example, in profiles B-B and D-D positive and negative overshot is clearly observed in the transitions air/wood, which can lead to false maxima detection when the separation between timber lamellas is below the effective resolution of the tomogram. The overshot can be qualitatively explained as Gibbs ringing artefact (Archibald and Gelb 2002) introduced by the discontinuity in the Fourier domain between reconstructed and non-reconstructed spectral components.

\subsection{Optimum segmentation of glued and non-glued areas}

Figure 4 illustrates glue line assessment results for a typical glued timber sample. The central image is an average optic image of the inner lamellas of the open sample. Figures 4a, c, e and $\mathrm{g}$ are greyscale images $\hat{\mu}(x, z)$ obtained as results from the glue line readout algorithm. Generally three differentiated regions can be distinguished in the images, a dark grey region $R_{a}$ corresponding to values of $\mu_{\text {ext }}\left(h_{a}\right)$ where the air gap thickness was large enough to assess lack of glue without STMAP segmentation; a confusion region $R$ ? for very thin air gaps, where $\mu_{\text {ext }}\left(h_{g}\right)$ is plotted; and a wellglued region $R_{g}$ where $\mu_{\text {ext }}\left(h_{g}\right)$ is also plotted and the Xray attenuation coefficient is largest. Figures $4 b, d, f$ and $h$ are binary images $\hat{H}(x, z)$ (white: glued, black: non-glued) obtained after STMAP segmentation. For all output images most glue line pixels in $R_{\text {? }}$ and $R_{g}$ were assigned correctly to non-glued and glued material, respectively. 
Fig. 4 Glue line assessment results. $\mathbf{a}, \mathbf{c}, \mathbf{e}$ and $\mathbf{g}$ are greyscale images $\hat{\mu}(x, z)$ calculated according to Table 1 .

$\mathbf{b}, \mathbf{d}, \mathbf{f}$ and $\mathbf{h}$ are the corresponding binary images $\hat{H}(x, z)$

Abb. 4 Ergebnisse des Klebfugen-Auslesealgorithmus. $\mathbf{a}, \mathbf{c}, \mathbf{e}$ und $\mathbf{g}$ sind Graustufenbilder $\hat{\mu}(x, z)$ gemäß Tabelle 1. b, $\mathbf{d}, \mathbf{f}$ und $\mathbf{h}$ sind entsprechende Binärdarstellungen $\hat{H}(x, z)$
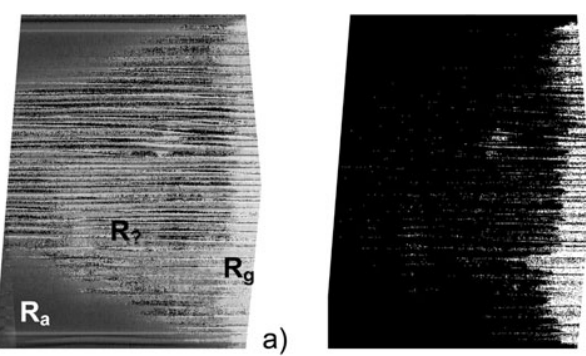

b)
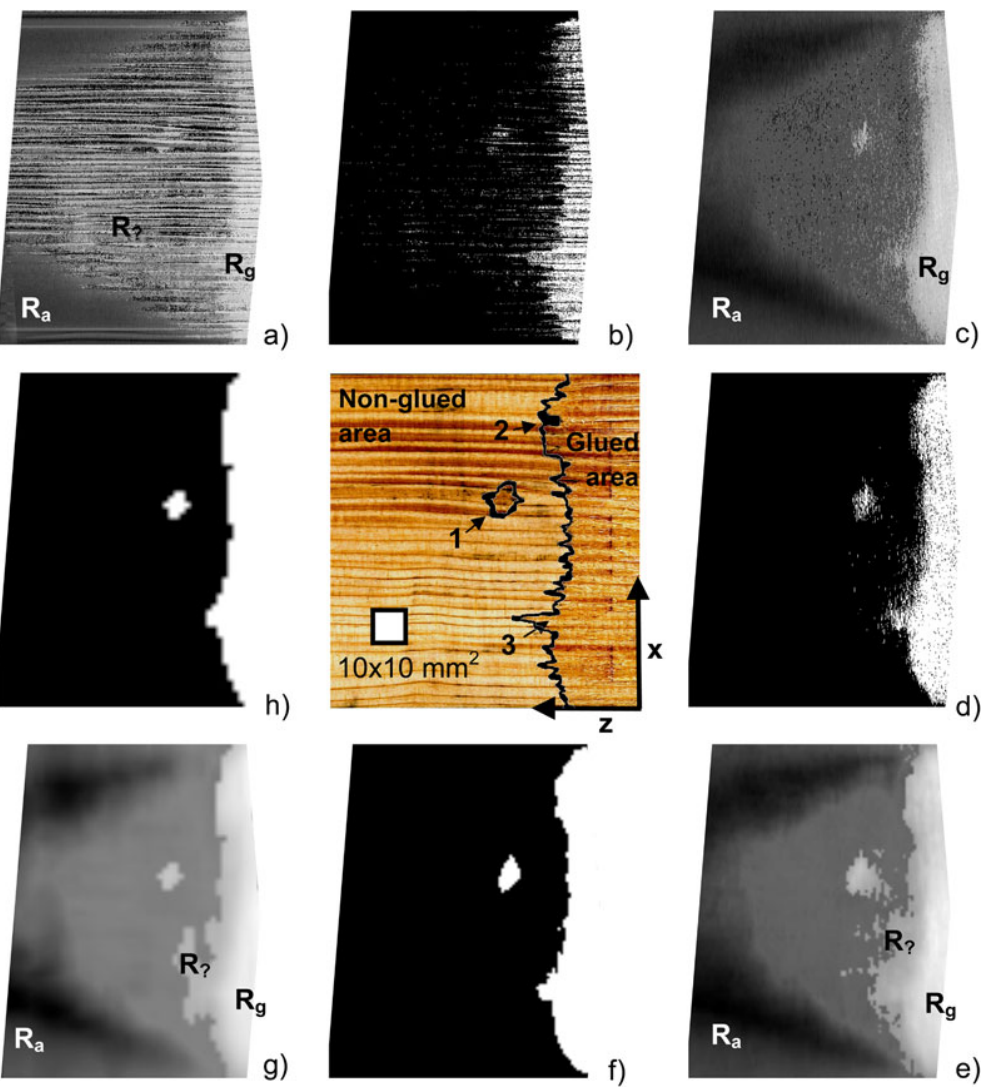

The reconstruction parameters had a direct impact on the final binary images. Figures $4 \mathrm{a}$ and $\mathrm{b}$ show results for full-angle reconstruction (1800 projections with $0.2^{\circ}$ steps), which resulted in the largest $R$ ? region and worst detection performance, with some false hits in both $R_{\text {? }}$ and $R_{g}$. The year ring pattern introduces alternating bright (EW) and dark (LW) horizontal stripes. This is a consequence of a mixture of the X-ray attenuation coefficients of wood and glue line for gap thicknesses below the measurement resolution. Figures $4 \mathrm{c}$ and $\mathrm{d}$ show limited-angle results (19 projections, angular range of $\pm 1.8^{\circ}$ ); a remarkable detection improvement is observed, with almost a total absence of $R_{\text {? }}$. The transition profile between glued and nonglued regions in Fig. 4d is smoother than in Fig. 4b. However, the streaky features in the transition profile of Fig. $4 \mathrm{~b}$ could not be matched reliably to those measured with optic means. Therefore, it is not clear whether they are really present in the sample or just artefacts. The smallest details that were successfully identified in both $\mu \mathrm{CT}$ and optic images, such as the small adhesive droplet (1) or features (2) and (3), have diameters of $5 \mathrm{~mm}$ or larger and are detected with both full-angle and limited-angle reconstruction.

A quantitative assessment of the adhesive detectability with respect to the heterogeneity of the surrounding wood material was performed in terms of a logarithmic contrastto-noise ratio (CNR) defined as follows:
$C N R=20 \log \left(\frac{\mu_{g}^{e}-\mu_{w}}{s_{\mu}}\right)$

where $\mu_{g}^{e}$ is the effective X-ray attenuation coefficient of the adhesive detected in the glue line; $\mu_{g}^{e}$ equals $\hat{\mu}$ in $R_{g}$. The CNR decreases for large grey level variations in wood or for small $\mu_{g}^{e}$, with the latter associated to glue line thicknesses under the resolution limits of the measurement. Figure 5 shows CNR statistics as a function of the angular range reconstructed. The CNR decreases monotonically with increasing number of reconstructed projections, for an angular range of about $\pm 2^{\circ}$ the observed CNR is between 20 and $25 \mathrm{~dB}$, for full-angle reconstruction it varies between 6 and $20 \mathrm{~dB}$ (smaller CNR values than $6 \mathrm{~dB}$ are assigned to $R$ ? according to $\kappa$ in Eq. 4). The CNR shows a sharp increase between 1701 (angular range of $\pm 170^{\circ}$ ) and $1800\left( \pm 180^{\circ}\right)$ projections. In the latter case the glue line plane is irradiated from both sides of the sample, thus causing an averaging by a factor of 2 of the glue line information that theoretically reduces the random noise level by $3 \mathrm{~dB}$. Best CNR is obtained for radiography (single projection across the glue line plane), which expresses the inherent trade-off in the reconstruction between contrast (CNR) and spatial resolution in the bonding plane. In general, 9 projections (angular range of $\pm 0.8^{\circ}$ ) were the minimum required to detect glue line features of one tenth of the sample thickness, best resolution was obtained for 19 projections $\left( \pm 1.8^{\circ}\right)$. Significant noise 
Fig. 5 Contrast to Noise Ratio (CNR) as function of limited angular range. Dashed lines are mean values for each glued timber sample measured, for one of them (solid line) confidence intervals are also plotted

Abb. 5 CNR in Abhängigkeit des eingeschränkten

Winkelbereichs. Gestrichelte Linien sind Mittelwerte für jede gemessene verklebte Holzprobe; Konfidenzintervalle sind für eine davon (ausgezogene Linie) auch gezeichnet

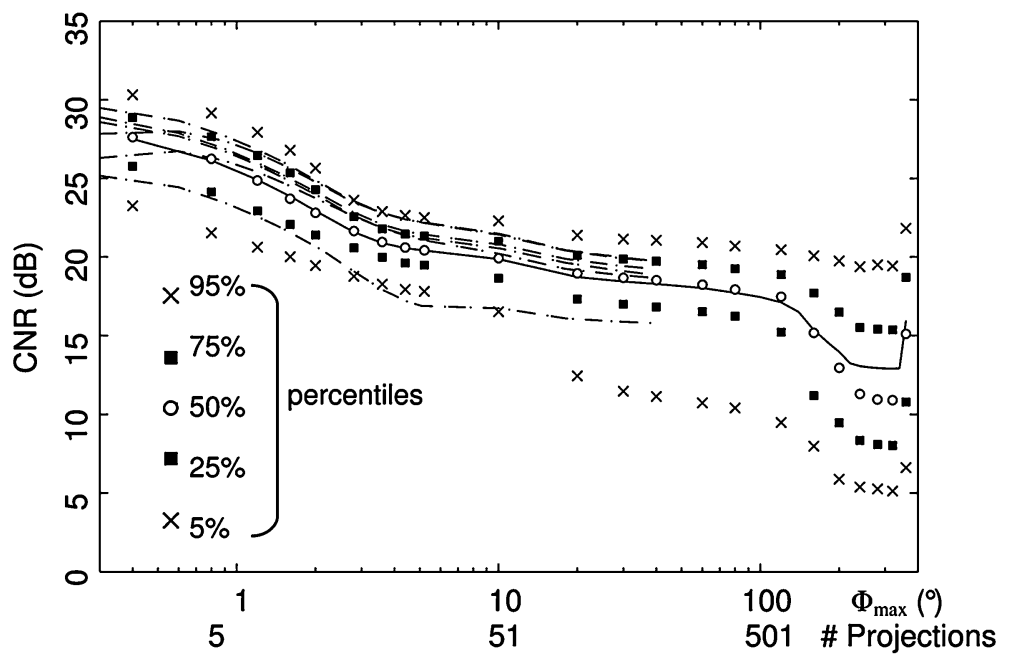

Table $1 \mu \mathrm{CT}$ parameters and computational costs corresponding to the results of Fig. 4

Tab. $1 \mu \mathrm{CT}$ Bestimmungsgrößen und Rechenaufwand der Ergebnisse in Abb. 4

\begin{tabular}{lllll}
\hline & Fig. 4a-b & Fig. 4c-d & Fig. 4e-f & Fig. 4g-h \\
\hline Angle step ( $\left.{ }^{\circ}\right)$ & 0.2 & 0.2 & 0.2 & 0.4 \\
No. projections & 1800 & 19 & 19 & 9 \\
Frame pixel size $u_{i} \times v_{j}\left(\mu \mathrm{m}^{2}\right)$ & $41 \times 41$ & $41 \times 41$ & $41 \times 820$ & $82 \times 1640$ \\
Reconstructed voxel $x_{i} \times y_{j} \times z_{k}\left(\mu \mathrm{m}^{3}\right)$ & $164 \times 41 \times 164$ & $164 \times 41 \times 164$ & $820 \times 41 \times 820$ & $1640 \times 82 \times 1640$ \\
$C N R(\mathrm{~dB})$ & 16 & 21 & 25 & 25 \\
$F O V^{e}(\mathrm{~mm})$ & 112 & 18 & 18 & 17 \\
Memory space X-ray frames $^{\mathrm{a}}$ & $14.4 \mathrm{~GB}$ & $25 \mathrm{MB}$ & $1.3 \mathrm{MB}$ & $150 \mathrm{~KB}$ \\
Memory space 3D tomogram & & $180 \mathrm{MB}$ & $7.3 \mathrm{MB}$ & $0.92 \mathrm{MB}$ \\
X-ray data acquisition time & $180 \mathrm{MB}$ & $1.3 \mathrm{~min}$ & $1.3 \mathrm{~min}$ & $36 \mathrm{~s}$ \\
Backprojection time & $120 \mathrm{~min}$ & $7.9 \mathrm{~min}$ & $15 \mathrm{~s}$ & $1.2 \mathrm{~s}$ \\
\hline
\end{tabular}

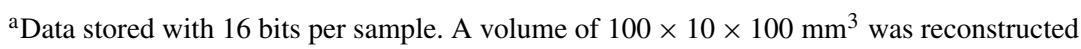

degradation with no further resolution improvement was observed above 51 projections $\left( \pm 5^{\circ}\right)$.

\subsection{Minimisation of reconstruction information}

The reconstruction information was minimised by enlarging the angular steps between projections $P_{\Phi}$ and by introducing an anisotropic binning factor in both frames and reconstructed tomograms. Angular steps of $0.15^{\circ}$ did not significantly improve the glue line assessment in comparison to steps of $0.2^{\circ}$. With $0.4^{\circ}$ steps the minimum number of projections could be reduced from 9 to 7 with a $3 \mathrm{~dB}$ CNR decrease; steps of $0.8^{\circ}$ or larger degraded the binary images. A reliable assessment was not possible using asymmetric angular projections. Binning in $v$ decreased the resolution in $z$ but also improved the CNR due to the averaging applied to the X-ray detector pixels. Figures $4 \mathrm{e}$ and $\mathrm{f}$ show the outcome of a reconstruction with 19 projections (angular range $\pm 1.8^{\circ}$ ) binning with a factor of 20 in $v$ (the sample-related pixel size is $41 \times 820 \mu \mathrm{m}^{2}$ ). A clear noise reduction is observed in comparison to Fig. 4d, with a CNR improvement of $4 \mathrm{~dB}$. However, it is also observed that the number of pixels belonging to $R$ ? increases, this effect can be interpreted as a resolution loss in $y$ which results in a smearing of the X-ray attenuation coefficient in the glue line. Binning in $u$ had a direct impact on the glue line readout; for binning factors larger than 2 the assessment was no longer possible. The glue line assessment performance was not affected by cropping the detector frame in $u$ to $F O V^{e}$ calculated with Eq. 2. Finally, the combination of several information reduction techniques was investigated. Figures $4 \mathrm{~g}$ and $\mathrm{h}$ were calculated with 9 projections spaced $0.4^{\circ}$, a binning factor of 2 in $u$ and a binning factor of 40 in $v$ (samplerelated pixel size of $82 \times 1640 \mu \mathrm{m}^{2}$ ). Even in this case, the adhesive droplet (1) and feature (3) were clearly recognisable.

Table 1 summarises the reconstruction settings used to compute Fig. 4 together with time and memory costs. 
The backprojection has a computational complexity of $O\left(N_{x} N_{y} N_{z} N_{\Phi}\right)$, where $N_{i}$ are the number of pixels in each dimension. The acquisition time was proportional to $N_{\Phi}$ and the exposition time of the X-ray detector. The total memory space for a $100 \times 100 \times 10 \mathrm{~mm}^{3}$ volume was reduced by a factor of 14000 between full-angle (Fig. 4a-b) and limitedangle reconstruction with multiple information reductions (Fig. $4 \mathrm{~g}-\mathrm{h}$ ). The acquisition time was reduced by 200 and the backprojection time by 38000 . The glue line assessment of Fig. $4 \mathrm{~g}-\mathrm{h}$ was implemented in less than $40 \mathrm{~s}$. It is possible to significantly reduce the computation times shown in Table 1; for example, by using a low level programming language or by parallelising the discussed algorithms. New developments in Graphic Processing Units (GPUs) allow for low-cost hardware parallelisation of the FDK algorithm with a time reduction by a factor of 80 with respect to a singlethreaded CPU (Sharp et al. 2007). Combining these optimisations, a real time implementation of the glue line assessment is feasible. The data acquisition times could be reduced by at least one order of magnitude by using a directional target X-ray source (for example XS160D, GE Sensing \& Inspection Technologies GmbH, Wunstorf, Germany), which allows for larger tube currents, therefore minimising the exposition times of the detector.

\subsection{Spatial resolution and detectability limits}

The effective full-angle spatial resolution across the glue line was measured with a self-developed algorithm that calculated the distance between $10 \%$ and $90 \%$ level cuts in the air/wood transitions (Fig. 3c). Statistics were calculated for the full air/wood transition area of 10 lamellas, with an excellent fit to a Gaussian distribution with a mean of $140 \mu \mathrm{m}$ and a std. deviation of $40 \mu \mathrm{m}$. The main resolution limit is given by the effective pixel size of the X-ray detector (according to the datasheet $105 \mu \mathrm{m}$ sample-related pixel size). The unsharpness of the X-ray beam is less than $20 \mu \mathrm{m}$ due to the large distance between source and sample. The effective sample-related pixel size can be reduced in about $25 \%$ by placing the sample closer to the X-ray tube. The geometry of this setup was chosen in order to achieve sufficient field of view for the full-angle measurements.

Figure 6 shows the stereomicroscopy measurements of the glue line thickness in the vicinity of the glued/non-glued transition and along a typical adhesively bonded glue line. The gap thickness readout was implemented with a similar algorithm to the one described in the next section. A total of 14 transitions were analysed. The results are summarised in Table 2. The mean air gap thickness in an interval of $1 \mathrm{~mm}$ from the transition was $15 \mu \mathrm{m}$, the adhesively bonded glue line thickness was $50 \mu \mathrm{m}$. Typical adhesive joint thicknesses in a $10 \mathrm{~mm}$ interval separated by at least $10 \mathrm{~mm}$ from the transition oscillated between 100 and $200 \mu \mathrm{m}$. The air gap was only thicker than $150 \mu \mathrm{m}$ at distances from the transition that were greater than $20 \mathrm{~mm}$. The position error be-
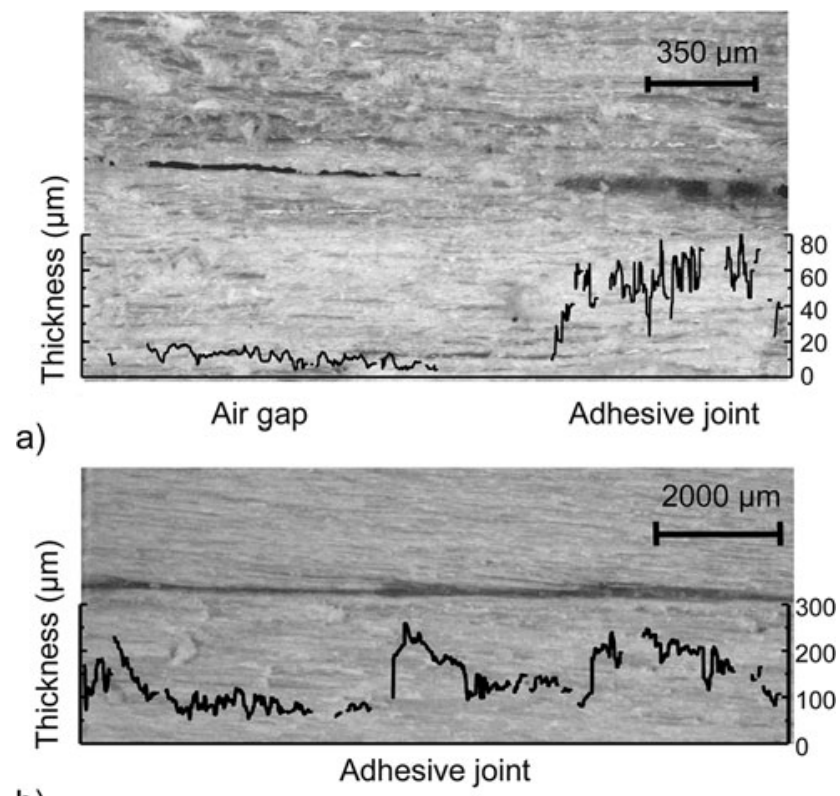

b)

Fig. 6 Glue line thickness characterisation using stereomicroscopy. a Transition between glued and non-glued timber. $\mathbf{b}$ Typical adhesive joint thickness profile

Abb. 6 Charakterisierung der Dicke der Klebfuge mittels Stereomikroskopie. a Übergang zwischen verklebtem und nicht verklebtem Holz. b Dickenprofil einer typischen Leimschicht
Table $2 \mu \mathrm{CT}$ spatial resolution across the bonding plane in comparison to stereomicroscopy results

Tab. 2 Räumliche Auflösung der $\mu \mathrm{CT}$ quer durch die Leimschicht im Vergleich zu Ergebnissen mittels

Stereomikroskopie

\begin{tabular}{ll}
\hline Parameter & Mean estimated value $(\mu \mathrm{m})$ \\
\hline$\mu \mathrm{CT}$ sample-related pixel size & 41 \\
$\mu \mathrm{CT}$ effective sample-related pixel size & 105 \\
Stereomicroscopy effective pixel size & $<5$ \\
Glue line thickness (1 mm from transition) & $35-60$ \\
Air gap thickness (1 mm from transition) & $10-20$ \\
Glue line thickness (>10 mm from transition) & $100-200$ \\
Air gap thickness (>20 mm from transition) & $>150$ \\
Transition positioning error between stereomicroscopy and $\mu \mathrm{CT}$ & $1000-2000$ \\
\hline
\end{tabular}


Fig. $7 \mu \mathrm{CT}$ glue line topology assessment. a Gap thickness map. b Open board photograph. c Tomoslice for profile A-A. d Comparison between $\mu \mathrm{CT}$ and optic air gap thickness determination

Abb. 7 Messung der

Klebfugendicke mittels $\mu \mathrm{CT}$. a Abbildung der Spaltdicke. b Photographie der aufgebrochenen Lamellen. c Schnittbild für Profil A-A. d Vergleich zwischen $\mu \mathrm{CT}$ und optisch ermittelter Luftspaltdicke

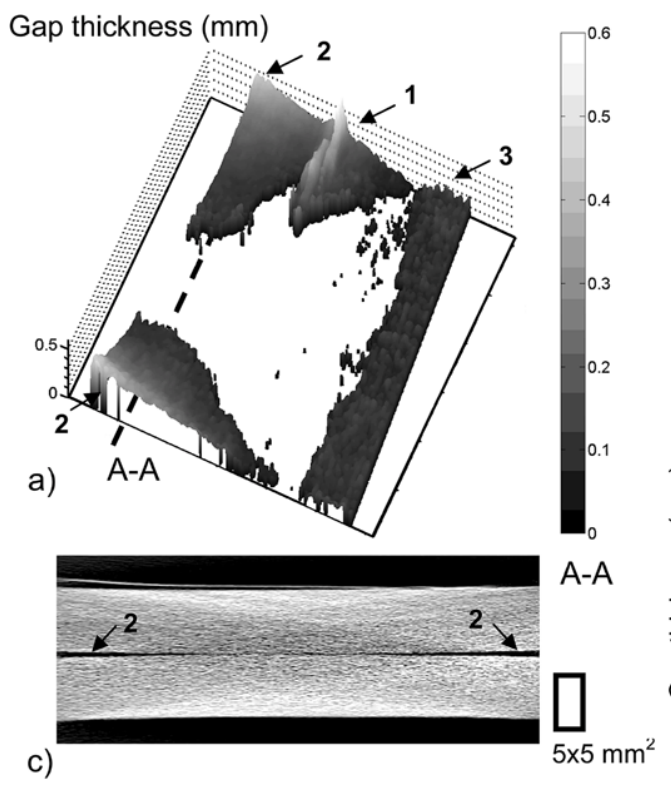

b)
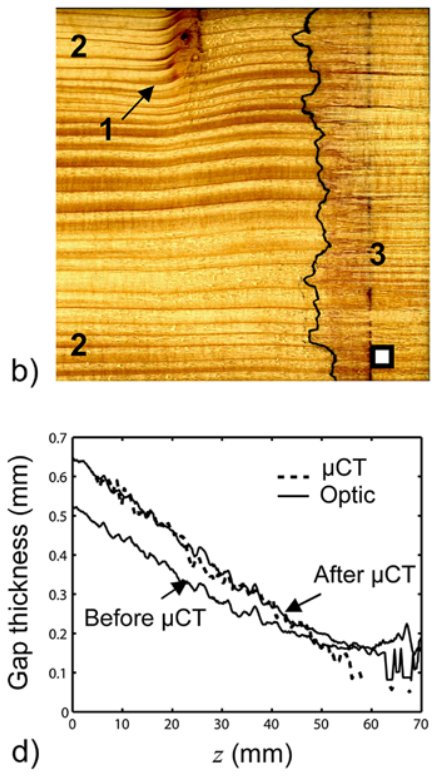

tween transitions measured with $\mu \mathrm{CT}$ and stereomicroscopy was typically smaller than $2 \mathrm{~mm}$. From these results it can be deduced that the $\mu \mathrm{CT}$ method detects the presence or absence of adhesive in glue lines of thicknesses down to half the effective sample-related pixel size. In the vicinity of the transition, the thin air gap between timber lamellas falls well below the resolution of the tomograms and cannot be detected. However, the presence or absence of adhesive in these confusion regions $R_{\text {? }}$ can still be assessed with the segmentation algorithms previously described.

\subsection{Gap topology assessment}

Next, the extension of the glue line readout algorithm for gap topology assessment between wood lamellas is discussed. The digital resolution of the tomograms across the glue line ( $y$ direction) was increased by a Fourier domain interpolation. The gap thickness between glued timber lamellas was computed for each position $(x, z)$ of the bonding plane by recording the width of the positive or negative peak observed in the glue line, thresholded with a cut value $\mu_{c u t}(x, z, h)$ :

$$
\begin{aligned}
& \mu_{c u t}\left(h_{g}\right)=\mu_{w}+\frac{t_{g}}{100}\left[\mu_{\text {ext }}\left(h_{g}\right)-\mu_{w}\right] \\
& \mu_{c u t}\left(h_{a}\right)=\mu_{w}-\frac{t_{a}}{100}\left[\mu_{w}-\mu_{\text {ext }}\left(h_{a}\right)\right]
\end{aligned}
$$

where $t_{g}$ and $t_{a}$ are percentage thresholds for glued and nonglued material, respectively. They depend on the effective contrast of adhesive and air with respect to wood, related to $\lambda$ with Eq. 4. Rewriting $\left|\mu_{\text {ext }}\left(h_{a}\right)-\mu_{w}\right| \lambda<\mid \mu_{\text {ext }}\left(h_{g}\right)-$ $\mu_{w} \mid$ as $\left|\mu_{\text {ext }}\left(h_{a}\right)-\mu_{c u t}\left(h_{a}\right)\right|<\left|\mu_{\text {ext }}\left(h_{g}\right)-\mu_{\text {cut }}\left(h_{g}\right)\right|$ it follows that $\lambda=\left(1-t_{a} / 100\right) /\left(1-t_{g} / 100\right)$. Best results were observed for $t_{a}=50 \%$ and $t_{g}=75 \%$.
Figure 7 a shows a typical $\mu \mathrm{CT}$ gap thickness topology assessment, an optic image of the open sample is shown in Fig. 7b. An angular range of $\pm 2.6^{\circ}$ (35 projections) was chosen. A small knot on the board surface (1) introduced large $\mathrm{X}$-ray attenuation coefficients in the $\mu \mathrm{CT}$ images, which could be misinterpreted as glued material. However, the gap topology assessment reveals the surface topology of the defect, providing information about its nature. The air gap thickness (2) and the adhesive joint (3) topology could also be investigated. Due to the presence of an aluminium spacer at middle length of the sample (Fig. 1) it was observed that the wood lamellas were slightly curved, being in close contact at the centre of the width and showing an opening (2) at the edges (Fig. 7c). Air gap thickness profiles measured optically at the edges of the sample and gap thickness profiles evaluated from $\mu \mathrm{CT}$ tomograms (Fig. 7d) were compared. Two optic measurements were performed immediately before and after $\mu \mathrm{CT}$ measurement, a $100 \mu \mathrm{m}$ variation was observed between both of them. This change was most probably due to the manipulation of the sample and creep deformation due to the tension induced by the aluminium spacer. The $\mu \mathrm{CT}$ results were in close agreement with the optic data for air gap thicknesses larger than $150 \mu \mathrm{m}$, which corresponds to the effective resolution limit of the $\mu \mathrm{CT}$ measurement.

\section{Results on glulam lamellas of thicknesses used in construction}

Finally, glue line assessment results for glued timber lamellas of the thicknesses typically found in glulam constructions (EN 386:2001) are shown. Two lamellas of $250 \times$ $170 \times 32.5 \mathrm{~mm}^{3}$ were glued together to form a glulam beam 
Fig. $8 \mu \mathrm{CT}$ assessment of glulam. a Full-angle (top left) and limited-angle (top right) tomoslices. $\mathbf{b}$ and $\mathbf{c}$ are corresponding $\hat{\mu}(x, z)$. d $\hat{H}(x, z)$ computed from (b). e Air-coupled ultrasound results Abb. $8 \mu$ CT Messungen an Brettschichtholz. a Schnittbilder für Vollwinkel (oben links) und eingeschränkten Winkelbereich (oben rechts). b und $\mathbf{c}$ sind entsprechende $\hat{\mu}(x, z)$. d $\hat{H}(x, z)$ berechnet aus (b). e Ergebnisse mit luftgekoppeltem Ultraschall
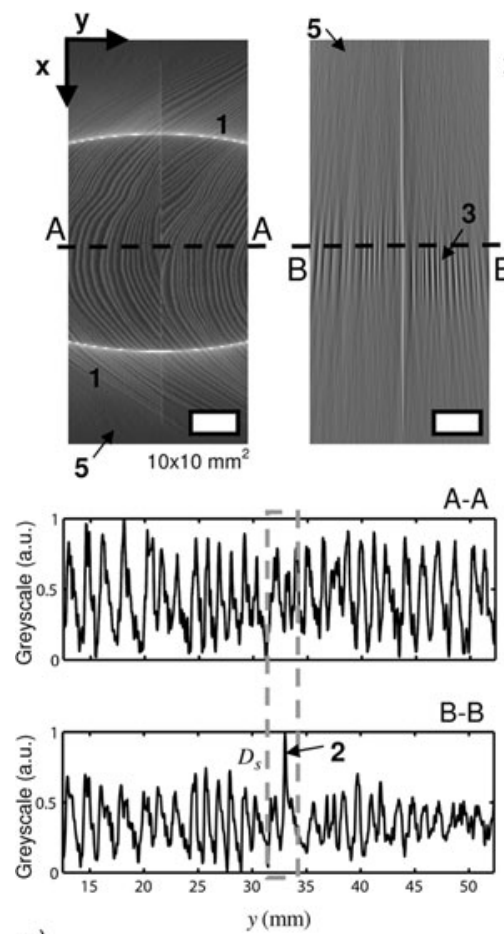

a)

()
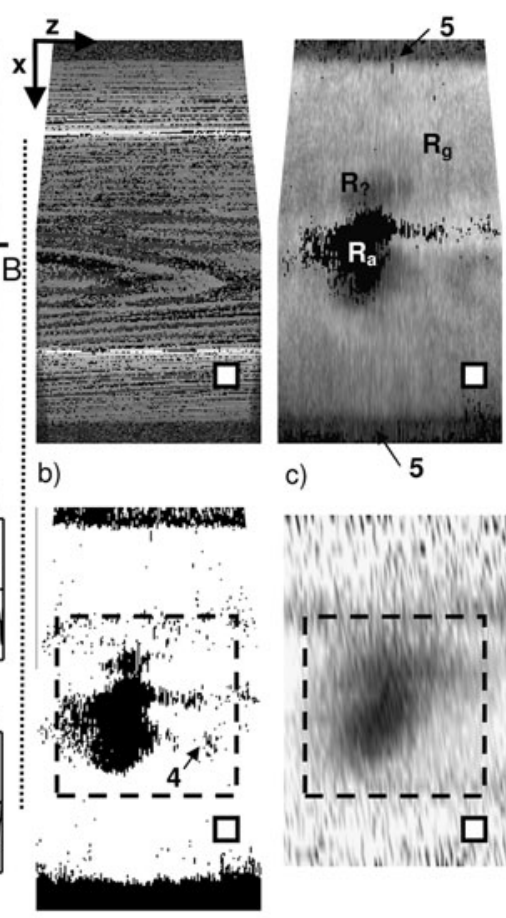

d)

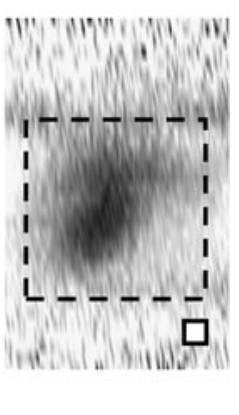

e) of $250 \times 170 \times 65 \mathrm{~mm}^{3}$. Adhesive was applied to the entire sample except for an $80 \times 80 \mathrm{~mm}^{2}$ region. A tube voltage of $80 \mathrm{kV}$ with a nominal power of $15 \mathrm{~W}$ was used, the detector pixel was hardware binned to $100 \mu \mathrm{m}$ for a sample-related pixel size of $87 \mu \mathrm{m}$ and an exposition time of $0.5 \mathrm{~s}$ was chosen. 1800 projection frames were recorded with $0.2^{\circ}$ steps. Figure 8 a shows reconstructed tomoslices using 1800 and 19 projections (no frame binning, voxel size of $697 \times 87 \times 697 \mu \mathrm{m}^{3}$ ). The region (1) fell outside the fieldof-view only in the full-angle case; (5) was reconstructed outside the glued timber sample. The year rings were essentially parallel to the adhesive joint, which introduced strong greyscale variations across the glue line. In contrast to Fig. 3, the year ring pattern of both lamellas did not match in most of the bonding plane. In the full-angle case, the EW/LW transitions present in the glue joint hided the adhesive information (profile A-A) and the glue line assessment failed to detect the lamination faults (Fig. 8b). The limited-angle reconstruction revealed the presence of adhesive (2) in the glue line (profile B-B) and filtered out to a great extent the year ring structure except for EW/LW transitions (3) highly parallel to the glue line (angle smaller than $1.8^{\circ}$ ). The remaining wood structure did not compromise the imaging of the bonding plane if a small assessment interval was used; $\left|D_{s}\right|=2 \mathrm{~mm}$ was sufficient. Figures $8 \mathrm{c}$ and d show limitedangle glue line assessment results. The non-glued region was successfully identified and the EW/LW transitions introduced only a marginal number of noisy pixels (4) in the binary image. However, the measured non-glued region was smaller (about $30 \times 70 \mathrm{~mm}^{2}$ ) than the defect area defined during the manufacturing of the sample (dashed square). A probable reason is that the adhesive may have penetrated into the defect area during the pressing of the glued timber lamellas. The $\mu \mathrm{CT}$ images were compared to an aircoupled ultrasound (ACU) measurement of the same sample (Fig. 8e) according to Sanabria et al. (2010b). A decrease of ultrasonic amplitude revealed a reduced defect area that closely matched the position and extension observed with the $\mu \mathrm{CT}$ assessment.

\section{Conclusion}

It was shown that Limited-angle Microfocus X-ray Computed Tomography is an interesting alternative for glue line assessment of timber constructions; inspection of pairs of 100 and $170 \mathrm{~mm}$ wide glued timber lamellas is possible. A simple limited-angle FDK reconstruction with 7 to 19 projection frames in an angular range of $\pm 0.6^{\circ}$ to $\pm 1.8^{\circ}$ was sufficient to segment the bonding plane into glued and non-glued areas with a spatial resolution of $5 \mathrm{~mm}$. The small angular ranges allowed for fields of view of less than $20 \mathrm{~mm}$, making the measurement independent of the height and length of the inspected beam. Moreover, the limitedangle reconstruction efficiently filters out undesired wood structure while preserving the glue line information. Accurate segmentation of the glue line was possible in all inspected samples, even if similar X-ray attenuation was observed for adhesive and latewood regions. The measurement 
time was reduced to $40 \mathrm{~s}$ for a $100 \times 100 \mathrm{~mm}^{2}$ bonding plane by reconstructing only a reduced number of anisotropically binned projections. A detailed analysis of the resolution of the $\mu \mathrm{CT}$ tomograms together with stereomicroscopy measurements of the glue line thickness revealed that, in the proximity of the transitions between glued and non-glued areas, the air gap separation between timber lamellas fell well below the $105 \mu \mathrm{m}$ resolution of the $\mu \mathrm{CT}$ measurement. Edge distortion effects in the air/wood transition can lead to a confusion region in which glued material is falsely detected. A STMAP algorithm was developed and allowed for a robust probabilistic discrimination of glued material from thin air gaps. The complete measurement procedure was able to detect the presence or the lack of adhesive down to glue lines of $50 \mu \mathrm{m}$ thickness. Delaminations and air gap thickness topology could be assessed for separations larger than $150 \mu \mathrm{m}$ between timber lamellas. These limits did not compromise the detectability of lamination faults for thin glue lines of 100 to $200 \mu \mathrm{m}$ obtained with hydraulic pressing.

Future research work should extend the implementation to an industrial environment. The described method can be applied separately to individual laminations; therefore, its extension to multilayered glulam assessment is immediate. The geometric arrangement described should be improved to allow for practical positioning of large samples with respect to the X-ray tube and detector. A real time implementation of the measurement procedure seems feasible, with the exposition times in the detector being reduced by using a directional target source. New developments in Graphic Processing Units (GPUs) should allow for low-cost real time implementation of the glue line assessment algorithms.

Acknowledgement This research has been supported by the Swiss National Science Foundation under contract 200021-115920. The authors acknowledge the work of Fabian Binkert, Danniel Gómes and Dominik Mächler for the optical characterisation of the samples and analysis of $\mu \mathrm{CT}$ data, and the tutorials of Dr. Iwan Jerjen and Dr. René Mooser in CT reconstruction software.

\section{References}

Archibald R, Gelb A (2002) A method to reduce the Gibbs ringing artifact in MRI scans while keeping tissue boundary integrity. IEEE Trans Med Imaging 21(4):305-319

Berglind H, Dillenz A (2003) Detection of glue deficiency in laminated wood with pulse thermography. J Wood Sci 49(3):216-220

Bhandarkar SM, Luo XZ, Daniels R, Tollner EW (2006) A novel feature-based tracking approach to the detection, localization, and $3-\mathrm{D}$ reconstruction of internal defects in hardwood logs using computer tomography. Pattern Anal Appl 9(2-3):155-175

Bucur V (2003) Nondestructive characterization and imaging of wood. Springer, Berlin

Choi MY, Park JH, Kim WT, Kang KS (2008) Detection of delamination defect inside timber by sonic IR. In: Proc of the Society of Photo-optical Instrumentation Engineers (SPIE), Orlando, FL, USA, 6939 U306-U309
Dill-Langer G, Aicher S, Bernauer W (2005) Reflection measurements at timber glue-lines by means of ultrasound shear waves. OttoGraf-J 16:273-283

Dunky M, Niemz P (2002) Holzwerkstoffe und Leime: Technologie und Einflussfaktoren. Springer, Berlin

EN 386:2001 Glued laminated timber-Performance requirements and minimum production requirements

EN 391:2001 Glued laminated timber-Delamination test of glue lines

EN 14080:2005 Timber structures-Glued laminated timberRequirements

Entacher K, Planitzer D, Uhl A (2007) Towards an automated generation of tree ring profiles from CT-images. In: Proc of the 5th international symposium on image and signal processing and analysis, New York, NY, USA, pp 174-179

Espinoza GR, Hernandez R, Condal A, Verret D, Beauregard R (2005) Exploration of the physical properties of internal characteristics of sugar maple logs and relationships with CT images. Wood Fiber Sci 37(4):591-604

Feldkamp LA, Davis LC, Kress JW (1984) Practical cone-beam algorithm. J Opt Soc Am A, Opt Image Sci Vis 1(6):612-619

Hasenstab A (2006) Integritätsprüfung von Holz mit dem zerstörungsfreien Ultraschallechoverfahren. Dissertation, Technische Universität Berlin

Hu LJ, Gagnon S (2007) X-ray-based scanning technique for nondestructive evaluation of finger-joint strength. In: Proc of the 15th international symposium on NDT of wood, Deluth, MN, USA

Kabir MF, Schmoldt DL, Schafer ME (2002) Time domain ultrasonic signal characterization for defects in thin unsurfaced hardwood lumber. Wood Fiber Sci 34(1):165-182

Kak AC, Slaney M (1988) Principles of computerized tomographic imaging. IEEE Press, New York

Longuetaud F, Mothe F, Leban JM (2007) Automatic detection of the heartwood/sapwood boundary within Norway spruce (Picea abies (L) Karst) logs by means of CT images. Comput Electron Agric 58:100-111

Maeva E, Severina I, Bondarenko S, Chapman G, O’Neill B, Severin F, Maev RG (2004) Acoustical methods for the investigation of adhesively bonded structures: a review. Can J Phys 82(12):9811025

Mannes D, Sonderegger W, Hering S, Lehmann E, Niemz P (2009a) Non-destructive determination and quantification of diffusion processes in wood by means of neutron imaging. Holzforschung 63(5):589-596

Mannes D, Niemz P, Lehmann E (2009b) Tomographic investigations of wood from macroscopic to microscopic scale. Wood Res 54(3):33-44

Morigi MP, Casali F, Bettuzzi M, Bianconi D, Brancaccio R, Cornacchia S, Pasini A, Rossi A, Aldrovandi A, Cauzzi D (2007) CT investigation of two paintings on wood tables by Gentile da Fabriano. Nucl Instrum Methods Phys Res, Sect A, Accel Spectrom Detect Assoc Equip 580(1):735-738

Niemz P, Kucera LJ, Flisch A, Blaser E (1997) Application of computertomography (CT) on wood defects and decay. Holz Roh- Werkst 55:279-280

Niemz P, Poblete H, Cuevas H, Flisch A (1999) Klebfugenfestigkeit von keilverzinktem. Holzforsch Holzverwert 51:79-81

Oja J (2000) Evaluation of knot parameters measured automatically in CT-images of Norway spruce (Picea abies (L) Karst). Holz RohWerkst 58(5):375-379

Osterloh K, Raedel C, Zscherpel U, Meinel D, Ewert U, Buecherl T, Hasenstab A (2008) Fast neutron radiography and tomography of wood. Insight 50(6):307-311

Rinnhofer A, Petutschnigg A, Andreu JP (2003) Internal log scanning for optimizing breakdown. Comput Electron Agric 41(1-3):7-21

Sanabria SJ, Mueller C, Neuenschwander J, Niemz P, Sennhauser U (2010a) Air-coupled ultrasound as an accurate and reproducible 
method for bonding assessment of glued timber. Wood Sci Technol. doi:10.1007/s00226-010-0357-z

Sanabria SJ, Neuenschwander J, Niemz P, Sennhauser U (2010b) Structural health monitoring of glued laminated timber with a novel air-coupled ultrasound method. In: Proc of the 11th World conference on timber engineering, Riva del Garda, Trentino, Italy

Scheepers G, Moren T, Rypstra T (2007) Liquid water flow in Pinus radiata during drying. Holz Roh- Werkst 65(4):275-283

Schmoldt DL, He J, Abbott AL (2000) Automated labeling of log features in CT imagery of multiple hardwood species. Wood Fiber Sci 32(3):287-300

Sepulveda P, Oja J, Gronlund A (2002) Predicting spiral grain by computed tomography of Norway spruce. J Wood Sci 48(6):479-483
Sharp GC, Kandasamy N, Singh H, Folkert M (2007) GPU-based streaming architectures for fast cone-beam CT image reconstruction and demons deformable registration. Phys Med Biol 52(19):5771-5783

Sirr SA, Waddle JR (1999) Use of CT in detection of internal damage and repair and determination of authenticity in high-quality bowed stringed instruments. Radiographics 19(3):639-646

Solodov I, Pfleiderer K, Busse G (2004) Nondestructive characterization of wood by monitoring of local elastic anisotropy and dynamic nonlinearity. Holzforschung 58(5):504-510

Van Trees HJ (2001) Detection, estimation and modulation theory, Part I. Wiley, New York 